\title{
Prescribing tests must have curriculum support
}

This article was published in the following Dove Press journal:

Advances in Medical Education and Practice

6 May 2013

Number of times this article has been viewed

\section{Thomas I Lemon \\ Rupali D Shah}

School of Medicine, Cardiff University, University Hospital of Wales, Cardiff, Wales
Correspondence: Thomas I Lemon School of Medicine, Cardiff University, University Hospital of Wales, Heath Park, Cardiff CFI 4 4XW, Wales

Email lemonti@cf.ac.uk

\section{Dear Editor}

Gordon, Catchpole and Baker ${ }^{1}$ have discussed and investigated a very interesting, currently relevant, subject in medical education; particularly with the introduction of the prescribing test for undergraduates trialled in the UK this year and set to become a fully-fledged part of the curriculum and assessment criteria for 2014 graduates. $^{2}$ It would of course be of great interest to compare the themes discussed in this paper and see they how would compare to recent graduates in late 2014.

Anecdotal evidence suggests these prescribing tests have not been popular with students, and a recent poll (by the authors of this letter) of students whom had taken this test in 2013, added credence to this with 63 out of $76(83 \%)$ stating they found the prescribing test of no benefit. ${ }^{3}$ The issue with the prescribing test is it seen by students as yet another barrier which they must cross and 'tick the box' rather than being an essential skill that will reduce iatrogenic incidents.

Unfortunately, prescribing tests seem to be a last ditch attempt by medical educators to convey the message to the public that medical students have been trained and examined in prescribing, whilst arguably not being not the case. The authors would argue, that the first group of students to take this will have more than likely received no formal training, tutorials or lectures regarding the skills of prescribing - the skills will have been expected to have been picked up on already busy placements. If students are to be expected to take an exam in prescribing then some provision must be made within the curriculum to allow them to learn the skills needed to pass this exam. To reduce iatrogenic medication errors and have competent medical undergraduates then prescribing skills must be instigated from an early stage in the undergraduate curriculum.

Comparison can be made to communication skills which have only recently been given a central role in the UK undergraduate curriculum, perhaps prescribing is next.

\section{Disclosure}

The authors report no conflicts of interest in this correspondence. 


\section{References}

1. Gordon M, Catchpole K, Baker P. Human factors perspective on the prescribing behaviour of recent medical graduates: implications for educators. Advances in Medical Education and Practice. 2013;4:1-9.

2. British Pharmacological Society [http://www.prescribe.ac.uk]. Prescribing Skills Assessment Available from http://www.prescribe. ac.uk/psa/. Accessed March 18, 2013.
3. Lemon TI, Shah RD [http://www.meducation.net]. Prescribing skill assessment and students opinion Available from https://www.meducation. net/blog_posts/55-Prescribing-Skills-Assessment-and-students-opinion. Accessed March 22, 2013. 


\section{Authors' response}

\section{Morris Gordon ${ }^{1,2}$ \\ Ken Catchpole ${ }^{3}$ \\ Paul Baker ${ }^{1,4}$}

'Faculty of Health and Social Care, University of Salford, Salford, UK; ' 2 Department of Paediatrics, Blackpool Victoria Hospital, Blackpool, UK; ${ }^{3}$ Department of Surgery, Cedars-Sinai Medical Center, Los Angeles, CA, USA; ${ }^{4}$ North Western Deanery, Manchester, UK

Correspondence: Morris Gordon

Mary Seacole Building, MS 3.46, Frederick Road Campus,

University of Salford, Greater Manchester, M6 6PU, UK

Email morris@betterprescribing.com

Shah and Lemon's stance that more complete prescribing education should be embedded within the undergraduate curriculum is one that we would share wholeheartedly. However, we do not share their quite negative view of the national prescribing assessment, but rather we have a sense of ambivalence. Assessment has always and still is the 'tail that wags the dog' with students extremely canny at preparing themselves to progress by successfully completing such assessments. The need for such an examination is justified by the variations amongst medical schools in their approach to assessments, with many offering a cursory role for prescribing within summative assessment. We agree that only time will tell if the completion of this exam improves technical prescribing skill and impacts the almost constant rates of prescribing errors seen amongst the medical hierarchy in previous large scale studies. ${ }^{1}$

Our enthusiasm is a little stunted when the nature of the examination questions is considered. ${ }^{2} \mathrm{~A}$ review of the examples published reveal an assessment that pays no attention to the non-technical skills involved in prescribing, essentially ignoring the thrust of our research. ${ }^{3} \mathrm{~A}$ technically perfect prescriber can and will still persistently carry out aberrant prescribing. ${ }^{1}$ We therefore fear that the assessment seems to represent a lost opportunity to explore such issues.

Previously, we have designed and assessed through a randomized controlled trial, a new prescribing education intervention. ${ }^{4}$ One of the innovative elements of this programme, as well as a focus for questions within the assessments, was scenarios regarding recognition of sources of medication errors. We believe that consideration of such elements is just one example of how non-technical skill competencies could be considered within the national prescribing assessment. This would allow a more complete view of prescribing ability to be ascertained, as well as leading undergraduate curriculum and teaching development to enhance safety in the way that Shah and Lemon lay out.

\section{Disclosure}

The authors report no conflicts of interest in this correspondence.

\section{References}

1. Dornan T, Ashcroft D, Heathfield H, et al. An in-depth investigation into causes of prescribing errors by foundation trainees in relation to their medical education: EQUIP study. Final report to the General Medical Council. 2009. University of Manchester: School of Pharmacy and Pharmaceutical Sciences and School of Medicine.

2. British Pharmacological Society [http://www.prescribe.ac.uk]. Prescribing Skills Assessment. Available from http://www.prescribe. ac.uk/psa/. Accessed March 18, 2013.

3. Gordon M, Catchpole K, Baker P. Human factors perspective on the prescribing behaviour of recent medical graduates: implications for educators. Advances in Medical Education and Practice. 2013;4:1-9.

4. Gordon M, Chandratilake M, Baker P. Improved junior paediatric prescribing skills after a short e-learning intervention: a randomised controlled trial. Archives of Diseases in Childhood. 2011;96:1191-1194.

\section{Publish your work in this journal}

Advances in Medical Education and Practice is an international, peerreviewed, open access journal that aims to present and publish research on Medical Education covering medical, dental, nursing and allied healthcare professional education. The journal covers undergraduate education, postgraduate training and continuing medical education including emerging trends and innovative models linking education, research, and healthcare services. The manuscript management system is completely online and includes a very quick and fair peer-review system. Visit http://www.dovepress.com/testimonials.php to read real quotes from published authors. 